\title{
Percepção da autoimagem e satisfação corporal como fatores decisórios na escolha e percepções de nutricionistas de diferentes estereótipos
}

\section{Giovana Santarosa Cassiano*; Felipe Rodrigues de Oliveira; Joana Pereira Carvalho-Ferreira; Priscila Koritar; Diogo Thimoteo da Cunha.}

\begin{abstract}
Resumo
O objetivo do estudo foi avaliar a confiança e o calor de modelos de nutricionistas de diferentes características e relacionar essa avaliação com a percepção da autoimagem e satisfação corporal. Os 152 participantes avaliaram seis modelos de nutricionistas (variando em gênero, idade e perfil corporal), na perspectiva da teoria Social Content Stereotype com avaliação da confiança e calor. Para avaliação da autoimagem, os participantes realizaram o teste de figuras de silhuetas e o "Questionário sobre a Forma Corporal", a fim de mensurar a satisfação e as preocupações com as formas corporais. Os resultados foram analisados por análise de testes de comparação de média. O modelo de nutricionista "Idoso Eutrófico" recebeu maior escore de confiança da amostra estudada, e a "Mulher Obesa" obteve maior escore de calor. Em relação a distorção da imagem corporal 18,4\% e 28,9\% da amostra possuíam, respectivamente, moderada e intensa distorção.
\end{abstract}

\section{Palavras-chave:}

estereótipo, confiança, autoimagem.

\section{Introdução}

Os estereótipos definidos pela sociedade nem sempre são verossímeis, e ainda que sejam, estereótipos causam pressão nos indivíduos afetados (FISKE et al., 2002). No caso do nutricionista, a sociedade, e os próprios profissionais, esperam que este seja magro (eutrófico) (ARAÚJO et al., 2015) além de existir, no mercado de trabalho, a segregação ocupacional oriunda de gênero, um dos maiores problemas enfrentado por mulheres (AEL et al., 2018). O objetivo do estudo foi a avaliar a confiança e calor de modelos de nutricionistas e a percepção da autoimagem e satisfação corporal.

\section{Resultados e Discussão}

Obteve-se amostra de 152 voluntários $(63,8 \%$ do sexo feminino), com média de 28,2 anos e média de IMC de $24,4 \mathrm{~kg} / \mathrm{m}^{2}$. Quanto aos resultados da avaliação da confiança e calor de diferentes modelos de nutricionistas, é visto na Tabela 1 que o perfil "Idoso Eutrófico" obteve maior confiança, assim como os demais estereótipos eutróficos, o que sustenta a ideia de a sociedade esperar que um nutricionista seja magro (ARAÚJO, et. al., 2015). Além disso, pode haver nesse resultado - que atribui maior confiança a uma figura masculina - a segregação ocupacional (AEL et al., 2018). Já em relação a dimensão calor (no sentido "warmth"), a "Mulher Obesa" obteve a maior média, e na dimensão confiança, ambas as figuras obesas receberem menores médias, mantendo a concepção de que os obesos são atribuídos menores: competência, potencial de liderança, chance de sucesso profissional e salários (O'BRIEN, et. al. 2012).

Tabela 1. Resultados médios dos escores de confiança e calor (escala de 3 a 15).

\begin{tabular}{lcc} 
& $\begin{array}{c}\text { Escores da } \\
\text { Dimensão }\end{array}$ & $\begin{array}{c}\text { Escores da } \\
\text { Confiança }\end{array}$ \\
& Dimensão Calor \\
\hline Mulher obesa & $10,6(2,78)$ & $12,37(2,28)$ \\
Mulher eutrófica & $11,42(2,36)$ & $11,01(2,29)$ \\
Homem obeso & $9,28(3,04)$ & $9,45(2,9)$ \\
Homem eutrófico & $11,17(2,25)$ & $9,51(2,71)$ \\
Idosa eutrófica & $12(2,35)$ & $11,71(2,12)$ \\
Idoso eutrófico & $11,97(2,38)$ & $10,39(2,56)$ \\
\hline
\end{tabular}

No tocante a distorção da imagem corporal, os resultados são apresentados no gráfico a seguir:

Figura 1. Percentual de participantes de acordo com a classificação de distorção da imagem corporal

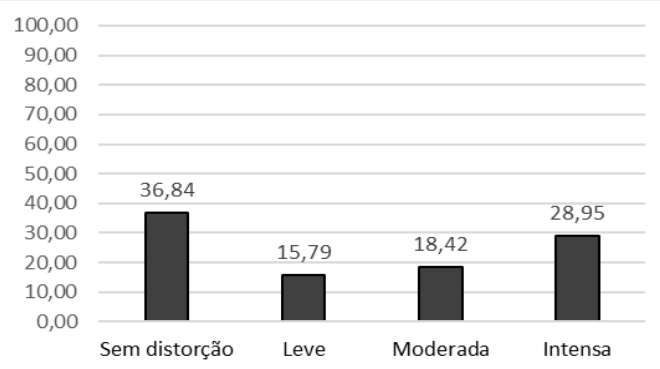

É visto que $36,84 \%$ dos participantes não apresentaram distorção da imagem corporal, 15,79\% apresentaram distorção leve, 18,42\% distorção moderada e 28,95\% demonstraram distorção intensa da imagem corporal, o que mostra um alto índice de indivíduos com distorção de imagem na amostra estudada.

\section{Conclusões}

Dentre os diferentes estereótipos do profissional nutricionista avaliados, o "Idoso Eutrófico" apresentou maior confiança e a "Mulher Obesa" maior calor. Quanto a imagem corporal, destaca-se o fato de $28,95 \%$ da amostra possuir uma intensa distorção da autoimagem, o que pode ter influenciado nos resultados da avaliação da confiança e calor dos modelos de nutricionistas. É necessária a atuação das entidades de classe para desmitificar o papel do nutricionista e etiologia da obesidade.

Agradecimentos

Conselho Nacional de Desenvolvimento Tecnológico e Científico

$(\mathrm{CNPq})$.

AEL, Cristina Garcia; CUADRADO, Isabel; MOLERO, Fernando. The Effects of Occupational Status and Sex-Typed Jobs on the Evaluation of Men and Women . 2018.

DE ARAÚJO, K.L; LOPES, P. G. P; SOARES, F. M. C. Suffering and prejudice: paths taken by obese nutritionists seeking weight loss . no.9. 2015. O'Brien, K. S., Latner, J. D., Ebneter, D., \& Hunter, J. A. (2012). Obesity discrimination: the role of physical appearance, personal ideology, and anti-fat prejudice. International Journal Of Obesity, 37, 455. 